\title{
Blue Planet Prize 2021 to Professor Mohan Munasinghe for Pioneering 'Sustainomics': An Integrative, Transdisciplinary Framework for Sustainable Development
}

\author{
Pradeep Kumar Dubey ${ }^{1}$
}

(c) The Author(s), under exclusive license to Springer Nature Singapore Pte Ltd. 2021

In times of global environmental changes, pollution, and population overshoot, the sustainable utilization of finite natural resources within the carrying capacity of our biosphere is of paramount significant for ensuring the well-being of both people and planet (Ember et al. 2020; Wackernagel et al. 2021). Innovative concepts and practices entrenched in resource governance and sustainability principles are essential for human survival in the Anthropocene. As resource consumption must not exceed planetary replenishment capacity, sustainable strategies based on circular economy principles and positive behavioural changes for fostering responsible production and consumption are imperative for global sustainable development (Liu et al. 2015; Xu et al. 2020). A transition towards the 'sustainomics' framework is indeed an urgent need-thanks to Professor Mohan Munasinghe for pioneering this integrative and transdisciplinary framework, where developmental challenges are viewed from environmental, economic, and social perspectives (Munasinghe 2010; 2011; 2019). This societal transition based on mindful resource consumption helps in achieving the UN-Sustainable Development Goals (UN-SDGs) in a timely manner, as well as in meeting the needs of future generations (Munasinghe 2019). For his pioneering work on sustainomics during the last 50 years, Prof. Munasinghe (Fig. 1) was awarded the coveted 'Blue Planet Prize' 2021 by the Asahi Glass Foundation, Japan to recognize the noble efforts of "individuals or organizations who have made significant contributions to the resolution of global environmental problems" (https://www.af-info.or.jp/en/blueplanet/).

The sustainomics framework includes novel ideas like 'balanced inclusive green growth' (BIGG) and 'millennium consumption goals' (MCG). BIGG shows how nations could

Pradeep Kumar Dubey

pradeep.dubey4@bhu.ac.in

1 Institute of Environment and Sustainable Development, Banaras Hindu University, Varanasi 221005, India find sustainable development paths in accordance with their development status (Munasinghe 2019). The MCG concept asks the rich nations to adopt sustainable lifestyles to reduce their overuse and wastage of planetary resources, and thereby free those resources to help the poor. The MCG became a building block for SDG-12 (responsible consumption and production). During the last few decades, Prof. Munasinghe has practically applied these concepts worldwide, using environmental economics and sustainability principles (Munasinghe 2010; 2011; 2019).

$\mathrm{He}$ is the Founder Chairman of Munasinghe Institute for Development (MIND), Sri Lanka (http://www.mohanmunas inghe.com/default.cfm). His research interests evolved from basic disciplines like engineering, physics, and economics, to application sectors like energy, water, transport, ICT, and environmental resources, and finally to multidisciplinary topics like poverty, disasters, climate change, and sustainable development. He received his BA and MA in engineering from Cambridge University, UK (1967), MS and Professional EE from Massachusetts Institute of Technology, USA (1969), PhD in solid state physics from McGill University, Canada (1973), and MA in development economics from Concordia University, Canada (1975). He served as Senior Advisor to the President of Sri Lanka; Senior Advisor for Sustainable Development, World Bank, USA; and Chairman, Presidential Expert Commission on Sustainable Sri Lanka 2030 Vision Report. He received many global awards, including decorations from Heads of five countries, and shared the 2007 Nobel Peace Prize, as Vice Chair, Intergovernmental Panel on Climate Change (IPCC). 


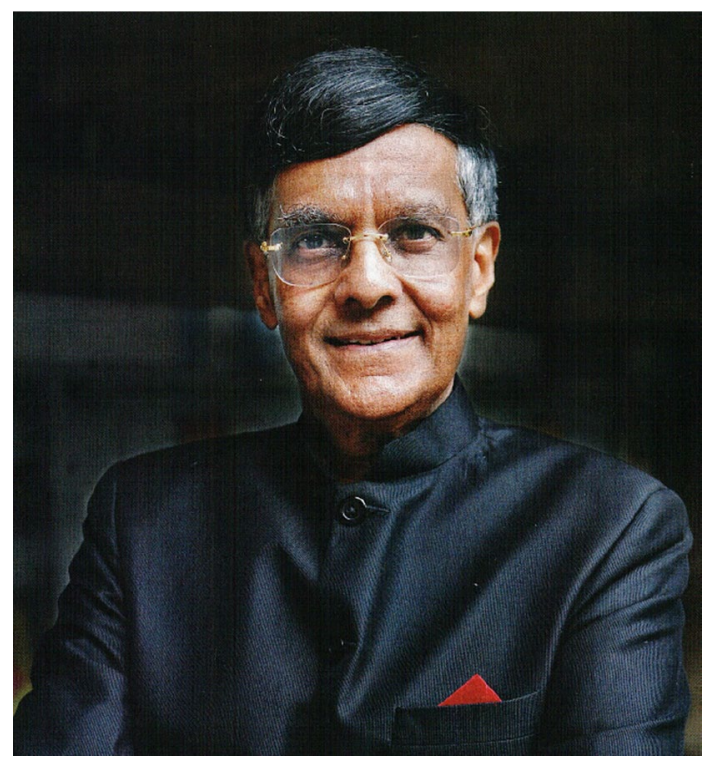

Fig. 1 Prof Mohan Munasinghe received the coveted Blue Planet Prize 2021 for pioneering the concept of 'sustainomics' for making development more sustainable. (Photo Credit: Mohan Munasinghe)

\section{References}

Ember CR, Ringen EJ, Dunnington J, Pitek E (2020) Resource stress and subsistence diversification across societies. Nat Sustain 3:737-745. https://doi.org/10.1038/s41893-020-0542-5

Liu J, Mooney H, Hull V, Davis SJ, Gaskell J, Hertel T, Lubchenco J, Seto KC, Gleick P, Kremen C, Li S (2015) Systems integration for global sustainability. Science 347:258832. https://doi.org/10. 1126/science. 1258832

Munasinghe M (2010) Can sustainable consumers and producers save the planet? J Ind Econ 14:4-6

Munasinghe M (2011) Addressing sustainable development and climate change together using sustainomics. Wiley Interdiscip Rev Clim Change 2:7-18. https://doi.org/10.1002/wcc.86

Munasinghe M (2019) Sustainability in the twenty-first century. Applying sustainomics to implement the sustainable development goals. Cambridge University Press (ISBN: 9781108241847)

Wackernagel M, Hanscom L, Jayasinghe P, Lin D, Murthy A, Raven P (2021) The importance of resource security for poverty eradication. Nat Sustain in Press. https://doi.org/10.1038/ s41893-021-00708-4

Xu Z, Chau SN, Chen X, Zhang J, Li Y, Dietz T, Wang J, Winkler JA, Fan F, Huang B, Li S, Wu S, Herzberger A, Tang Y, Hong D, Li Y, Liu J (2020) Assessing progress towards sustainable development over space and time. Nature 577:74-78. https://doi.org/10. 1038/s41586-019-1846-3

\section{Declarations}

Conflict of interest Author does not have any conflict of interest. 